\title{
Designing Human Antibodies by Phage Display
}

\author{
André Frenzel $^{a, b}$ Jonas Kügler ${ }^{b}$ Saskia Helmsing ${ }^{a}$ Doris Meier ${ }^{a}$ Thomas Schirrmann ${ }^{b}$ \\ Michael Hust $^{\mathrm{a}}$ Stefan Dübel ${ }^{\mathrm{a}}$ \\ ${ }^{a}$ Institute of Biochemistry, Biotechnology and Bioinformatics, Department of Biotechnology, Technische Universität Braunschweig, \\ Braunschweig, Germany; \\ bYumab GmbH, Braunschweig, Germany
}

\section{Keywords}

Human monoclonal antibodies - Phage display . Immunotherapy · In vitro evolution · Panning · scFv

\section{Summary}

With six approved products and more than 60 candidates in clinical testing, human monoclonal antibody discovery by phage display is well established as a robust and reliable source for the generation of therapeutic antibodies. While a vast diversity of library generation philosophies and selection strategies have been conceived, the power of molecular design offered by controlling the in vitro selection step is still to be recognized by a broader audience outside of the antibody engineering community. Here, we summarize some opportunities and achievements, e.g., the generation of antibodies which could not be generated otherwise, and the design of antibody properties by different panning strategies, including the adjustment of kinetic parameters.

(c) 2017 S. Karger GmbH, Freiburg

\section{Therapeutic Antibodies: Human Monoclonals Take the Lead}

Monoclonal antibodies are the largest and fastest growing group of 'biologicals' (i.e. therapeutic proteins). More than 50 antibody drugs have obtained marketing approval for clinical use and generated revenue of about USD 75 billion in 2013 [1]. More than 500 therapeutic antibodies and their derivatives are currently tested in clinical trials, with a focus on the treatment of cancer and autoimmune diseases. The first approved therapeutic antibody [2] was obtained by mouse hybridoma technology. Murine antibodies, how- ever, are recognized as foreign proteins by humans and therefore induce immune reactions against the therapeutic reagent (human anti-mouse antibody; HAMA) [3]. A solution to this problem was only brought by recombinant DNA technology. Using genetic engineering, the murine sequences were exchanged in parts of the molecule by the homologous human sequences. The result were 'chimeric' (with murine constant domains replaced by human constant domains) or 'humanized' antibodies (only the antigen-binding loops / complementarity determining regions (CDRs) were transferred to human variable region frameworks) [4, 5]. These engineered mouse antibodies dominated the first decade of therapeutic antibody approvals, while today it is preferred to use completely human antibodies from the start, thanks to a number of novel technologies allowing to identify them without the necessity to immunize humans. These are on the one hand transgenic animals, typically mice or rats, which carry genetically introduced human immunoglobulin loci while their own antibody genes were knocked out [6-8]. Consequently, after immunization they utilize this sequence repertoire to generate IgG from human germ-line sequences, thereby allowing to generate monoclonals by means of classical hybridoma technology. An even more radical way was introduced by the development of antibody phage display, which allowed for the first time to generate human antibodies completely in the test tube and without immunization. Inspired by the work of G.P. Smith on peptide display using filamentous phage [9], antibody phage display was development independently in Heidelberg by Breitling and Dübel [10], in Cambridge by McCafferty et al. [11], and in California by Barbas et al. [12]. The method is based on a physical link between function (antigen binding) and information (antibody gene) in a nanoparticle (the phage virus particle). To achieve this, the antigen binding parts of the antibodies, either as Fab (fragment antigen binding) $[13,14]$ or scFv (single chain fragment variable) [15-17], are genetically linked to the surface protein III (pIII) of the M13 phage and thus expressed on the surface of the virus particle. Mixtures of such phage particles, each en-

\section{KARGER}

() 2017 S. Karger GmbH, Freiburg

Fax +497614520714 


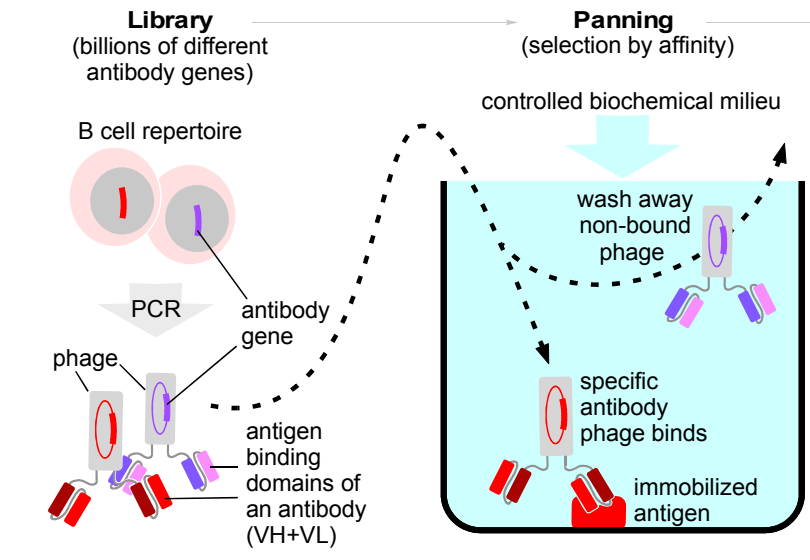

controlled biochemical milieu
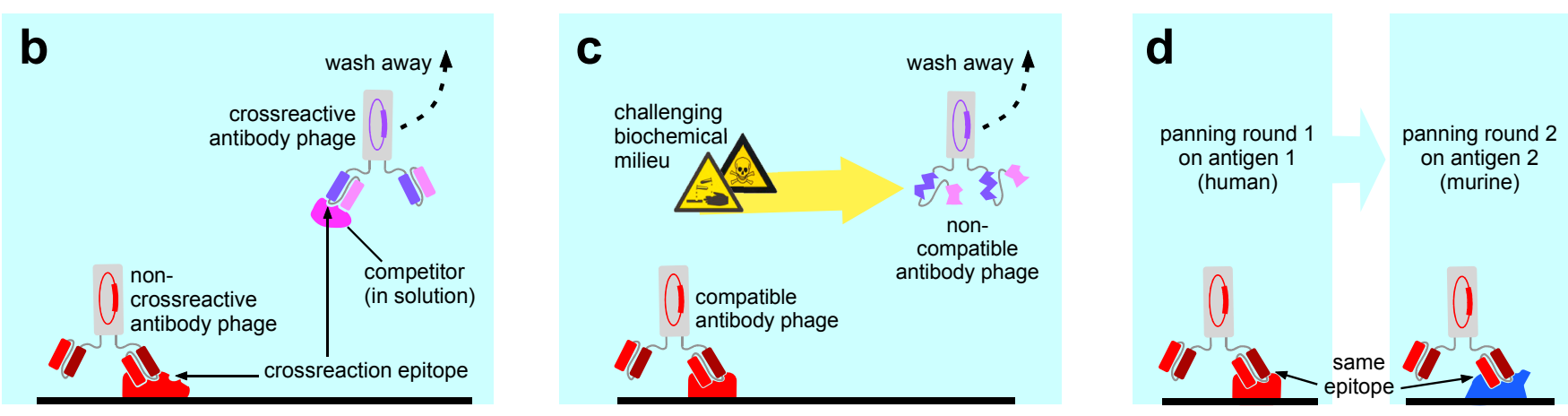

Fig. 1. Antibody phage display. a In an antibody phage particle, the antibody gene and the function it encodes (antigen binding) are physically linked. This allows the affinity selection of monoclonal human antibodies in the test tube (a process named 'panning'). b Panning in the presence of soluble competitor to deplete cross-reacting antibodies. c Panning under defined biochemical conditions selects only antibodies that are functional at these conditions. d Sequential panning rounds on two different but homologous antigens allow to functionally select antibodies that bind to a structural feature common to the two proteins.

coding and presenting a different antibody (i.e. an 'antibody library', fig. 1a left) can be produced which contain billions of different individual clones, allowing to mimic the entire naïve antibody repertoire. Out of these antibody libraries, the genes encoding those antibodies which can bind to the antigen can be selected by affinity enrichment on the antigen in vitro ('panning', fig. 1a). For practical reasons, the antibody genes are typically located on a separate plasmid ('phagemid') which has morphogenetic signals allowing its packaging into phage particles [10]. This enables the regulation and propagation of antibody genes independently from the phage genome, a prerequisite for the generation of stable libraries with high diversity. So far, six therapeutic antibodies generated by phage display are approved for therapy (table 1).

\section{Phage Display Can Deliver Antibodies which Cannot Be Obtained by Classical Immunization}

Antibody phage display not only allows the generation of entirely human antibody sequences, but, by relying on in vitro affinity selection which happens in a completely controllable biochemical milieu, it can also bypass some limitations of the immune sys- tem. For example, phage display can provide antibodies which could not be obtained by classical immunization, like antibodies against very small or non-immunogenic molecules $[18,19]$. The particular advantage of having control over the biochemical parameters during the very moment of selection can also be used to shape the specificity profile of an antibody right from the start. By adding a soluble competitor during the affinity selection on immobilized antigen, an undesired cross-reactivity can be excluded (fig. $1 \mathrm{~b}$ ). Using this approach, antibodies which are specific for a slight modification of the antigen, like a single functional group [18] or site specific phosphorylation [20], can be selected. By adding a cofactor inducing a certain allosteric conformation of an antigen, conformation-specific antibodies can be obtained [21]. The buffer used during the affinity selection step can also be adjusted precisely matching the requirements of the intended application (fig. 1c). Pre-absorption of the antibody phage on protein mixtures can also be employed to get rid of binders to unwanted cross-reactive epitopes.

On the other hand, a similar sequential incubation (panning) on similar or homologous proteins can be used to identify only those antibodies that recognize the structural similarities of the two proteins (fig. 1d). This is particularly interesting for the development 


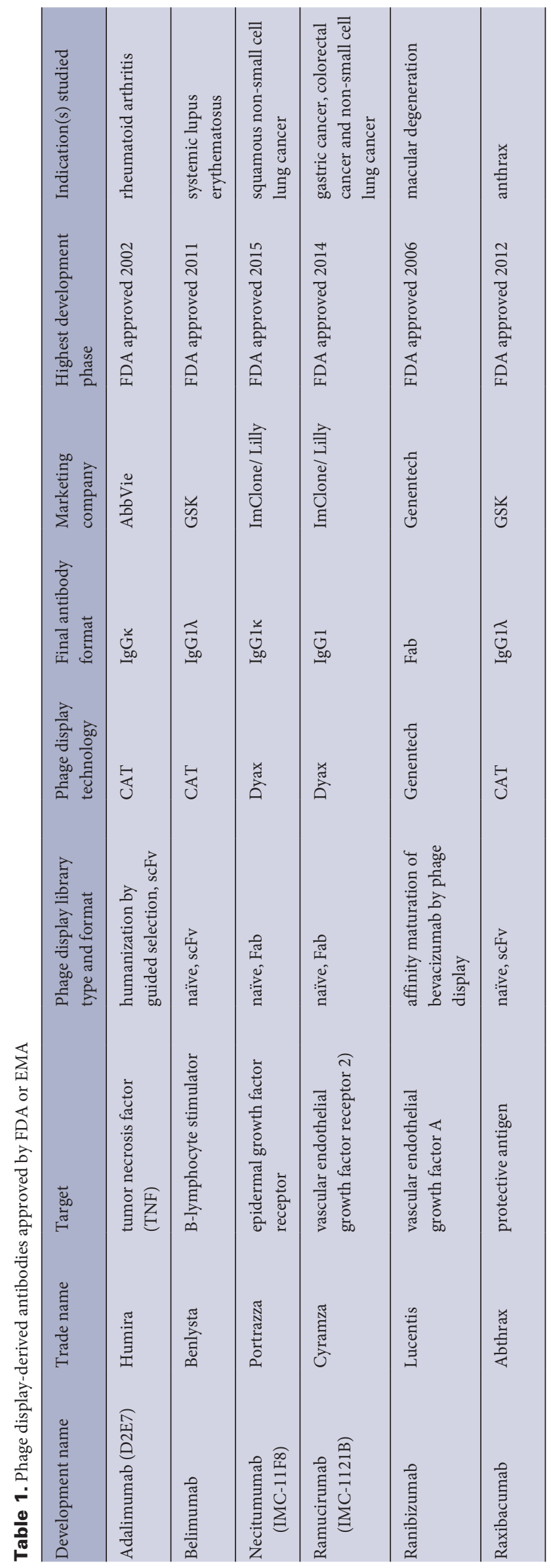

of therapeutic antibodies where the use of a suitable animal model is necessary to prove the function of an antibody intended to be developed towards clinical application. Here, by providing binding to the mouse analog of the human therapeutic target, development is simplified greatly. An overview of the opportunities added by the in vitro approach are given by [22].

Since the genetic information encoding the antibody is immediately available after elution from the affinity enrichment step, the antibody can immediately be produced in other formats if required, e.g. as IgG $[23,24]$, as scFv-Fc fusion with a choice of Fc parts from different species to match the subsequent assays [25], or in form of therapeutic fusion proteins expanding the effects of antibodies beyond of what can be achieved with IgG, like bispecific antibodies of fusion/conjugation to non-antibody effectors (fig. 1a, right). Even approaches using the antibody inside of cells to induce protein knock-downs have been proposed and successfully employed in vitro [26] and in vivo [27].

The first clinically approved therapeutic antibody obtained with the help of phage display was adalimumab (marketed as Humira ${ }^{\circledR}$ ), which neutralizes tumor necrosis factor and is mainly used against rheumatoid arthritis [28]. Today, it is the best-selling biological [1]. Six additional antibodies obtained from phage display have been approved as well, and more than 60 phage display-derived antibodies are currently undergoing clinical evaluation (for overview see Frenzel et al. [29]).

\section{Phage Display Libraries}

The essential resources for every successful phage display selection are high-quality antibody gene libraries. There are quite different philosophies and strategies for their generation. The easiest approach is the generation of 'immune libraries' from blood samples of immunized human donors $[31,30]$. Of course this strategy is particularly useful to obtain antibodies against the antigen against which the donors have already developed a specific B-cell reaction. Immune libraries typically contain more than 1 million different antibody sequences, but for obvious reasons, the availability of suitable human donors is quite limited, and the approach cannot be used for most of the desired therapeutic targets.

In contrast, the generation and use of libraries allowing the discovery of antibodies against all possible types of antigen requires much more effort. These 'universal' or 'single-pot' libraries must contain a repertoire of antibody genes several orders of magnitude more diverse compared to immune libraries in order to maintain good chances to provide appropriate binders for all possible antigen structures. Successful universal libraries typically contain more than 10 billion different antibody clones [32], making today's antibody phage display libraries the world's largest gene collections by a huge margin.

There are several approaches to produce the respective vast diversity of sequences. Synthetic universal libraries are based on randomized CDR regions inserted into fully synthetic framework sequences [14]. In the case of semi-synthetic libraries, a limited num- 
ber of naive variable regions of the heavy and light chain are used to insert randomized synthetic CDRs, typically with randomization of only the CDR3 of the heavy chain [33] and combined with a naïve repertoire of the other CDRs.

In our naïve universal IgM antibody libraries, the antibody-encoding genes are obtained from of B cells of a large number of donors and from various ethnic backgrounds, ensuring broad coverage of the world's allelic diversity. This vast repertoire is then cloned with provisions to minimize additional somatic hypermutations, ensuring that these antibody sequences are as close as possible to the germline genes, with the aim to decrease immunogenicity [32]. An advantage of this strategy compared to libraries with synthetic or semi-synthetic repertoires as well as to human-IgG transgenic mice is that all antibody sequences of such a naive universal IgM antibody - including the randomly synthesized CDR3 of the heavy chain - have already been expressed in a human body, and thus already have been subjected to selection for tolerance, producibility, and stability during B-cell differentiation. This strategy therefore aims to minimize the risk of adverse immune reactions against or by the antibody in subsequent clinical development.

\section{Phage Display Is a Robust and Reliable Source for Human Monoclonal Antibodies to Any Antigen}

In the past years, we have constructed and used several successive generations of antibody gene libraries for phage display. For strategies involving immunization, macaque libraries can be employed to generate in vivo affinity-matured antibodies where immunized human donors are not available. Since macaque VH and VL sequences have an extremely high homology to their human counterparts [34], they are a more obvious choice for the development of therapeutic antibodies than rodents. They have successfully been used to generate antibodies against the most dangerous toxins, like ricin [35], anthrax lethal factor [36], or various botulinum toxins [37, 38] but also against fungi [39], encephalitis viruses [40], or human proteins [41]. The last example also demonstrates the very high specificity achievable from phage display by design, since the discovered antibody is able to discriminate between very subtle conformation differences of Alzheimer peptide aggregates. Most recently, also the first protective antibody capable of neutralizing Marburg virus was obtained using this strategy [42].

Our first human naïve universal antibody gene library covering a broad ethnic donor spectrum was HAL4/7/8 [17]. The pHAL14 vectors used here allow both panning of phage antibodies and screening of soluble scFv fragments without re-cloning or re-formatting steps. This eliminated the artifact-prone phage ELISA from primary hit identification. These libraries were derived from 44 donors and contain around 5 billion independent clones. From these libraries, more than 1,000 antibodies for international proteome binder consortia [43-45], diagnostic antibodies [46, 47] as well as candidates for therapeutic applications [48-50] were selected. The next generation of human naïve antibody gene libraries
Table 2. Human phage display derived validated antibodies from HAL libraries from academic projects

\begin{tabular}{lcc}
\hline Origin of antigen & $\begin{array}{l}\text { Number of different } \\
\text { antigens }\end{array}$ & $\begin{array}{l}\text { Number of unique } \\
\text { validated binders }\end{array}$ \\
\hline Human & 315 & 2,023 \\
Other mammalia & 36 & 177 \\
Metazoa & 1 & 1 \\
Plants & 1 & 2 \\
Fungi & 13 & 41 \\
Bacteria & 56 & 319 \\
Virus & 13 & 60 \\
Haptens & 5 & 14 \\
Total & 440 & 2,637 \\
\hline
\end{tabular}

(HAL9/10) was derived from 98 donors with a broad spectrum of ethnic origins and contains a diversity of more than 10 billion independent clones [32]. The pHAL30 vector used for the construction of HAL9/10 allows an improved production of soluble scFv, in particular of scFv with kappa light chains. This library again was used to generate research antibodies to a wide variety of targets [51-53] as well as therapeutic antibody lead candidates in industry projects. So far, more than 1,000 individual, validated monoclonal human antibodies have been generated from Hal9/10 in academic projects and collaborations (table 2). Significantly, we did not observe limitations to generate human antibodies to human proteins, which represent the majority of the antigens used so far. However, we also have generated a number of antibodies to non-proteinous targets, like Legionella lipopolysaccharide [54], or to fungal beta(1,3)-glucan [19], where the in vitro approach not requiring antigen presentation within an immune system clearly represents an advantage.

\section{Different Applications Require Very Different Panning and Screening Approaches}

For research applications, the efforts which can be put into the generation of any specific antibody are usually quite limited and dictated by the deteriorating price tags of automated hybridoma labs and polyclonal rabbit facilities in low-wage countries. The typical task here is to generate antibodies to a large number of different antigens in high throughput for minimal effort $[43,44,55]$. To compete here, automation and miniaturization of phage display is essential. In international consortia (Affinity Proteome, Affinomics, SGC SH2 Pilot, and others), we have tested our phage display libraries for this task. Typically, per antigen, only 1 microtiter plate could be afforded to identify positive binders, forcing us to develop vectors, panning strategies, expression systems, and analysis assays to be able to reliably deliver hits within a maximum of 92 clones per antigen. One breakthrough improving efficiency was the development of Hyperphage, a helper phage greatly improving antibody display efficiency, resulting in both vastly improved success rates and reduced efforts [56]. 
Fig. 2. Affinity maturation and variation of association and dissociation constants by light chain shuffling. a Heavy chain of an antibody candidate was re-shuffled with the entire light chain repertoire of the naïve library (right panel: summarized plasmon resonance data of antigen binding). After screening with optimized conditions, antibodies with higher affinities were obtained (green dots). The parameters of the original antibody are indicated by the red dot. b plasmon resonance analysis of antigen binding of two human antibodies with similar affinity but different binding kinetics, obtained by light chain shuffling.

\section{a}
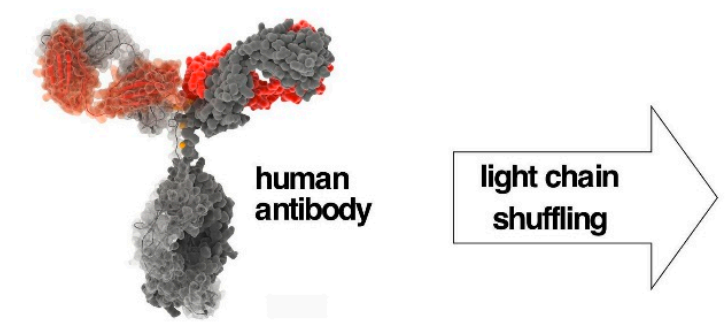

b

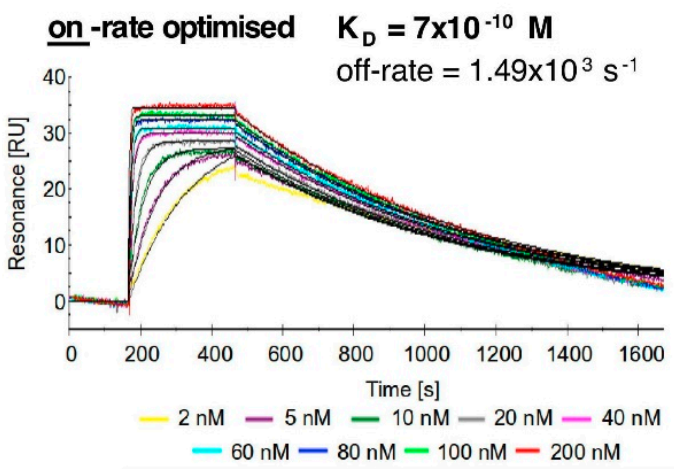

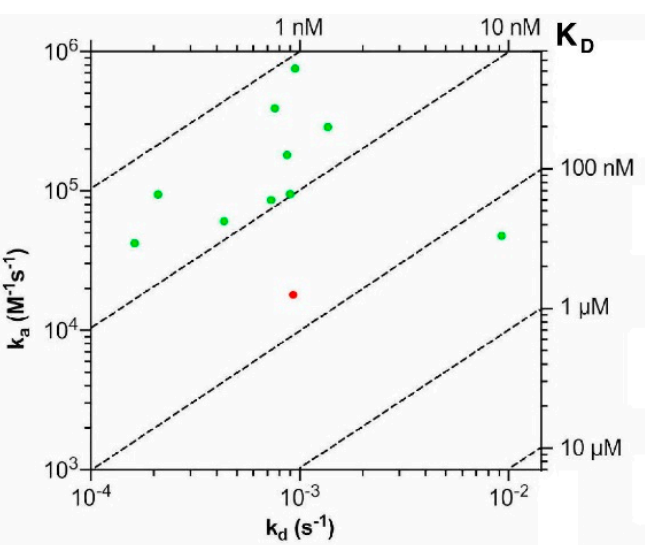

off-rate optimised: $\quad K_{D}=8 \times 10^{-10} \mathrm{M}$

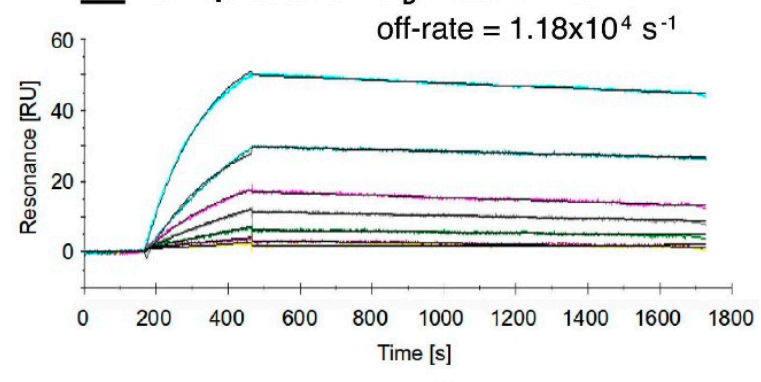

$-5 n M-10 n M-20 n M-40 n M-2 n M-60 n M-50 n M$
For customers in the industry, a very different strategy is usually employed. Here, the interest is typically focused to a single target, and an exhaustive sampling of the antibody repertoire ('deep screen') is intended to obtain the maximal number of candidates binding to the target, as attrition rates are known to be high in further preclinical development. The panning has to cope with different types of antigens such as proteins, peptides, virus-like particles, carbohydrates, whole cells, and others. Also, different strategies can be used sequentially in the successive panning rounds to focus the biochemical properties of the desired antibody to match several different conditions. A typical example are antibodies to cell surface receptors, which are desired to bind a particular epitope known to be functionally important. Here, successive panning steps (fig. 1d), for example, could combine a selection on a subdomain containing the epitope of interest with a panning on live cells to guarantee to get a binder which recognizes the correct in vivo conformation. Additionally, substances may be added as soluble competitor(s) to focus the panning results to antibodies without cross-reactivity to those (fig. 1b). Further, it is usual to employ different antibody gene libraries in parallel to exploit the available repertoires to the maximum. As animal models are typically required during later stages of the development, many selections include a step providing species cross-reactivity. This can be achieved by sequential panning on both the human and the animal homologue of the antigen (fig. 1d). As a consequence, in many panning campaigns, 16 or more different strategies are employed in parallel. During a deep-screen, more than 20,000 individual clones are typically analyzed, resulting in more than 100 different binders. Obviously, the effort for therapeutic antibody identification is much higher than for research antibodies, since antigen binding is just one feature of the candidates, while they also have to exhibit a biological effect, such as neutralization of virus particles or soluble ligands or tumor targeting. The identification of a high number of binding molecules of course enhances the probability of obtaining antibodies with desired properties. Therefore, it is very helpful to add a robust assay measuring the desired biological activity at a very early step of the development.

Alternatively, the candidates can be converted into the final format and expressed transiently in mammalian cells such as HEK293. This allows the screening of a large set of antibodies already in the final format for potential bioactivity and narrows down the candidate number before more laborious analyses.

Beside this, it is also possible to directly screen for functional binders to extracellular targets such as ion channels or G-proteincoupled receptors. These antigens can hardly be expressed in soluble form for classical solid-phase-coupled panning strategies, as they have several membrane-spanning regions and often only small extracellular loops. Here, transiently or stably transfected cells can be used as antigen carrier directly. Of course, extensive pre-adsorption with antigen-negative cells is necessary to remove antibody phage that bind to the unwanted targets on the cell surface. Additionally, intensive washing is needed to avoid enrichment of non-specific 'sticky' binders. This can be achieved by using several washing steps or by co-expression of a fluorescent marker gene together with the gene of interest and subsequent enrichment of binders to the target cells by flow cytometry [57].

Initial identification of antibody candidates is often followed by an optimization step to improve properties like affinity, stability, 
production yield, or others. In our hands, we prefer to achieve this by light chain shuffling $[58,59]$, since this allows to deliver antibodies which still are composed $100 \%$ from sequences which already have been in a human body before to lower the risk for unwanted immunogenicity or off-target reactions in the final clinical application, when compared to other optimization strategies relying on mutations. Light-chain shuffling combines the heavy chains of a panned subset of antibodies with the whole light-chain repertoire of the naïve library. These sub-libraries are then re-screened under modified conditions to obtain antibodies with advanced properties such as cross-species reactivity or higher affinity. This step exceeds the diversity limitation of any naïve immune system, where only very few light chains can be combined with any particular rearranged heavy chain during B-cell maturation. In contrast, phage display plus light chain shuffling practically exploits the entire theoretical combinatorial repertoire of $10^{18}$ different heavy/light chain combinations available from the human antibody genes. By choosing the panning conditions accordingly, for example affinity can be increased (fig. 2a) or kinetic properties like association and dissociation rates can be adjusted while keeping the same specificity and overall affinity (fig. 2b). This allows to quickly adapt the kinetic parameters of existing antibodies to different applications. While for therapy, a very slow dissociation is desirable in most cases, some biosensor applications benefit from antibodies with opposite properties, i.e. very fast association and quick dissociation rates, since this allows repeated measurements of antigen concentration without regeneration, as demonstrated for C-reactive protein detection on a microfluidic QCM sensor [60].
Diagnostic applications represent another growing field of interest for the development of recombinant designer antibodies. Here, the main features are sensitivity, selectivity/specificity, and stability. Therefore, strategies for diagnostic antibody discovery often include combined negative selections during panning to avoid various unwanted reactivities. Further, panning can be done under conditions of the final assay, e.g. to minimize the influence of matrix effects right from the start (fig. 1c). We have successfully employed this strategy to generate various anti-idiotype antibodies to quantify the serum levels of approved therapeutic antibodies to tumor necrosis factor $\alpha$. Here, intensive pre-adsorption with a mixture of different negative antigens - of course including other human IgGs - was used to identify several anti-idiotype antibodies which are now used in diagnostic kits on the market.

In conclusion, the capability to exactly define the biochemical conditions during the in vitro affinity enrichment of antibody phage from phage display libraries, combined with easy post-selection improvement by in vitro evolution, has vastly expanded our options to predefine the properties of antibodies far beyond what could be obtained before from animal-based generation or rational design.

\section{Disclosure Statement}

The authors have no conflict of interest to declare.

\section{References}

1 Ecker DM, Jones SD, Levine HL: The therapeutic monoclonal antibody market. MAbs 2015;7:9-14.

2 Emmons C, Hunsicker LG: Muromonab-CD3 (Orthoclone OKT3): the first monoclonal antibody approved for therapeutic use. Iowa Med J Iowa Med Soc 1987;77: $78-82$.

3 Kimball JA, Norman DJ, Shield CF, Schroeder TJ, Lisi P, Garovoy M, et al: OKT3 antibody response study (OARS): a multicenter comparative study. Transplant Proc 1993;25:558-560.

4 Hwang WYK, Foote J: Immunogenicity of engineered antibodies. Methods San Diego Calif 2005;36:3-10.

5 Presta LG: Engineering of therapeutic antibodies to minimize immunogenicity and optimize function. Adv Drug Deliv Rev 2006;58:640-656.

6 Fishwild DM, O’Donnell SL, Bengoechea T, Hudson DV, Harding F, Bernhard SL, et al: High-avidity human IgG kappa monoclonal antibodies from a novel strain of minilocus transgenic mice. Nat Biotechnol 1996;14:845-851.

7 Jakobovits A: Production of fully human antibodies by transgenic mice. Curr Opin Biotechnol 6 1995;561-566.

8 Osborn MJ, Ma B, Avis S, Binnie A, Dilley J, Yang X, et al: High-affinity IgG antibodies develop naturally in Ig-knockout rats carrying germline human IgH/Igk/ Ig $\lambda$ loci bearing the rat $\mathrm{CH}$ region. J Immunol Baltim Md 1950 2013;190:1481-1490.

$\checkmark$ Smith GP: Filamentous fusion phage: novel expression vectors that display cloned antigens on the virion surface. Science 1985;228:1315-1317.
10 Breitling F, Dübel S, Seehaus T, Klewinghaus I, Little M: A surface expression vector for antibody screening. Gene 1991;104:147-153.

11 McCafferty J, Griffiths AD, Winter G, Chiswell DJ: Phage antibodies: filamentous phage displaying antibody variable domains. Nature 1990;348:552-554.

12 Barbas I CF, Kang AS, Lerner RA, Benkovic SJ: Assembly of combinatorial antibody libraries on phage surfaces: The gene III site. Proc Natl Acad Sci U S A 1991; 88:7978-7982.

13 Hoet RM, Cohen EH, Kent RB, Rookey K, Schoonbroodt S, Hogan S, et al: Generation of high-affinity human antibodies by combining donor-derived and synthetic complementarity-determining-region diversity. Nat Biotechnol 2005;23:344-348.

14 Tiller T, Schuster I, Deppe D, Siegers K, Strohner R, Herrmann T, et al: A fully synthetic human Fab antibody library based on fixed VH/VL framework pairings with favorable biophysical properties. MAbs 2013; 5:445-470.

15 Schofield DJ, Pope AR, Clementel V, Buckell J, Chapple SD, Clarke KF, et al: Application of phage display to high throughput antibody generation and characterization. Genome Biol 2007;8:R254.

16 Vaughan TJ, Williams AJ, Pritchard K, Osbourn JK, Pope AR, Earnshaw JC, et al: Human antibodies with sub-nanomolar affinities isolated from a large nonimmunized phage display library. Nat Biotechnol 1996;14:309-314.
17 Hust M, Meyer T, Voedisch B, Rülker T, Thie H, ElGhezal A, et al: A human scFv antibody generation pipeline for proteome research. J Biotechnol 2011;152: 159-170.

18 Moghaddam A, Borgen T, Stacy J, Kausmally L, Simonsen B, Marvik OJ, et al: Identification of scFv antibody fragments that specifically recognise the heroin metabolite 6-monoacetylmorphine but not morphine. J Immunol Methods 2003;280:139-155.

19 Josewski J, Buchmeier S, Frenzel A, Tinnefeld P, Dübel S, Rau U: Generation of recombinant antibodies against the beta-(1,6)-branched beta- $(1,3)$-D-glucan schizophyllan from immunized mice via phage display. Biotechnol Res Int 2017;2017:8791359.

20 Blokzijl A, Zieba A, Hust M, Schirrmann T, Helmsing S, Grannas K, et al: Single chain antibodies as tools to study transforming growth factor- $\beta$-regulated SMAD proteins in proximity ligation-based pharmacological screens. Mol Cell Proteomics 2016;15:1848-1856.

21 Nizak C, Monier S, del Nery E, Moutel S, Goud B, Perez F: Recombinant antibodies to the small GTPase Rab6 as conformation sensors. Science 2003;300:984-987.

22 Bradbury ARM, Sidhu S, Dübel S, McCafferty J: Beyond natural antibodies: the power of in vitro display technologies. Nat Biotechnol 2011;29:245-254.

23 Jostock T, Vanhove M, Brepoels E, Van Gool R, Daukandt $\mathrm{M}$, Wehnert A, et al: Rapid generation of functional human IgG antibodies derived from Fab-onphage display libraries. J Immunol Methods 2004;289: $65-80$. 
24 Steinwand M, Droste P, Frenzel A, Hust M, Dübel S, Schirrmann T: The influence of antibody fragment format on phage display based affinity maturation of IgG. MAbs 2014;6:204-218.

25 Jäger V, Büssow K, Wagner A, Weber S, Hust M, Frenzel A, et al: High level transient production of recombinant antibodies and antibody fusion proteins in HEK293 cells. BMC Biotechnol 2013;13:52.

26 Marschall ALJ, Dübel S, Böldicke T: Specific in vivo knockdown of protein function by intrabodies. MAbs 2015;7:1010-1035.

-27 Marschall ALJ, Single FN, Schlarmann K, Bosio A, Strebe N, van den Heuvel J, et al: Functional knock down of VCAM1 in mice mediated by endoplasmatic reticulum retained intrabodies. MAbs 2014;6:13941401.

28 Osbourn J, Groves M, Vaughan T: From rodent reagents to human therapeutics using antibody guided selection. Methods San Diego Calif 2005;36:61-68

29 Frenzel A, Schirrmann T, Hust M: Phage display-derived human antibodies in clinical development and therapy. MAbs 2016;8:1177-1194.

30 Trott M, Weiß S, Antoni S, Koch J, von Briesen H, Hust $\mathrm{M}$, et al: Functional characterization of two scFv-Fc antibodies from an HIV controller selected on soluble HIV-1 Env complexes: a neutralizing V3- and a trimerspecific gp41 antibody. PloS One 2014;9:e97478.

-31 Welschof M, Terness P, Kipriyanov SM, Stanescu D, Breitling F, Dörsam H, et al: The antigen-binding domain of a human IgG-anti-F(ab')2 autoantibody. Proc Natl Acad Sci U S A 1997;94:1902-1907.

>32 Kügler J, Wilke S, Meier D, Tomszak F, Frenzel A, Schirrmann T, et al: Generation and analysis of the improved human HAL9/10 antibody phage display libraries. BMC Biotechnol 2015;15:10.

33 Pini A, Viti F, Santucci A, Carnemolla B, Zardi L, Neri $P$, et al: Design and use of a phage display library. Human antibodies with subnanomolar affinity against a marker of angiogenesis eluted from a two-dimensional gel. J Biol Chem 1998;273:21769-21776.

34 Pelat T, Hust M, Thullier P: Obtention and engineering of non-human primate (NHP) antibodies for therapeutics. Mini Rev Med Chem 2009;9:1633-1638.

35 Pelat T, Hust M, Hale M, Lefranc M-P, Dübel S, Thullier P: Isolation of a human-like antibody fragment $(\mathrm{scFv})$ that neutralizes ricin biological activity. BMC Biotechnol 2009;9:60

36 Pelat T, Hust M, Laffly E, Condemine F, Bottex C, Vidal D, et al: High-affinity, human antibody-like antibody fragment (single-chain variable fragment) neutralizing the lethal factor (LF) of Bacillus anthracis by inhibiting protective antigen-LF complex formation. Antimicrob Agents Chemother 2007;51:2758-2764.
37 Miethe S, Rasetti-Escargueil C, Avril A, Liu Y, Chahboun S, Korkeala H, et al: Development of human-like $\mathrm{scFv}-\mathrm{Fc}$ neutralizing botulinum neurotoxin E. PloS One 2015; 10:e139905

38 Miethe S, Mazuet C, Liu Y, Tierney R, Rasetti-Escargueil C, Avril A, et al: Development of germlinehumanized antibodies neutralizing botulinum neurotoxin A and B. PloS One 2016;11:e0161446.

39 Schütte M, Thullier P, Pelat T, Wezler X, Rosenstock P, Hinz D, et al: Identification of a putative Crf splice variant and generation of recombinant antibodies for the specific detection of Aspergillus fumigatus. PloS One 2009; 4:e6625.

40 Hülseweh B, Rülker T, Pelat T, Langermann C, Frenzel A, Schirrmann T, et al: Human-like antibodies neutralizing Western equine encephalitis virus. MAbs 2014;6: 718-727.

41 Droste P, Frenzel A, Steinwand M, Pelat T, Thullier P, Hust M, et al: Structural differences of amyloid- $\beta$ fibrils revealed by antibodies from phage display. BMC Biotechnol 2015;15:57.

42 Froude JW, Pelat T, Miethe S, Zak SE, Wec AZ, Chandran K, et al: Generation and characterization of protective antibodies to Marburg virus. MAbs 2017;9: 696-703.

43 Colwill K, Renewable Protein Binder Working Group, Gräslund S: A roadmap to generate renewable protein binders to the human proteome. Nat Methods 2011;8: 551-558.

44 Mersmann M, Meier D, Mersmann J, Helmsing S, Nilsson P, Gräslund S, et al: Towards proteome scale antibody selections using phage display. New Biotechnol 2010;27:118-128.

45 Kibat J, Schirrmann T, Knape MJ, Helmsing S, Meier $\mathrm{D}$, Hust $\mathrm{M}$, et al: Utilisation of antibody microarrays for the selection of specific and informative antibodies from recombinant library binders of unknown quality. New Biotechnol 2016;33:574-581.

46 Meyer T, Schirrmann T, Frenzel A, Miethe S, Stratmann-Selke J, Gerlach GF, et al: Identification of immunogenic proteins and generation of antibodies against Salmonella typhimurium using phage display. BMC Biotechnol 2012;12:29.

47 Fuchs M, Kämpfer S, Helmsing S, Spallek R, Oehlmann W, Prilop W, et al: Novel human recombinant antibodies against Mycobacterium tuberculosis antigen 85B. BMC Biotechnol 2014;14:68.

48 Wezler X, Hust M, Helmsing S, Schirrmann T, Dübel S: Human antibodies targeting CD30(+) lymphomas. Hum Antibodies 2012;21:13-28.
49 Goffin L, Fagagnini S, Vicari A, Mamie C, Melhem H, Weder B, et al: Anti-MMP-9 antibody: a promising therapeutic strategy for treatment of inflammatory bowel disease complications with fibrosis. Inflamm Bowel Dis 2016;22:2041-2057.

50 Schmitt LC, Rau A, Seifert O, Honer J, Hutt M, Schmid $S$, et al: Inhibition of HER3 activation and tumor growth with a human antibody binding to a conserved epitope formed by domain III and IV. MAbs 2017;9: 831-843.

51 Rohrbeck A, Fühner V, Schröder A, Hagemann S, Vu $\mathrm{X}-\mathrm{K}$, Berndt $\mathrm{S}$, et al: Detection and quantification of ADP-ribosylated RhoA/B by monoclonal antibody. Toxins 2016;8:100.

52 Wirsing L, Klawonn F, Sassen WA, Lünsdorf H, Probst C, Hust M, et al: Linear discriminant analysis identifies mitochondrially localized proteins in Neurospora crassa. J Proteome Res 2015;14:3900-3911.

53 Postel S, Deredge D, Bonsor DA, Yu X, Diederichs K, Helmsing S, et al: Bacterial flagellar capping proteins adopt diverse oligomeric states. eLife 2016: DOI: 10.7554/eLife.18857.

54 Kuhn P, Thiem S, Steinert M, Purvis D, Lugmayr V, Treutlein U, Plobner L, Leiser RM, Hust M, Dübel S: Human anti-lipopolysaccharid (LPS) antibodies against Legionella with high species specificity. Human Antibodies 2017;9;26:29-38.

55 Dübel S, Stoevesandt O, Taussig MJ, Hust M: Generating recombinant antibodies to the complete human proteome. Trends Biotechnol 2010;28:333-339.

56 Rondot S, Koch J, Breitling F, Dübel S: A helper phage to improve single-chain antibody presentation in phage display. Nat Biotechnol 2001;19:75-78.

57 Ferreri AJM, Illerhaus G, Zucca E, Cavalli F; International Extranodal Lymphoma Study Group: Flows and flaws in primary central nervous system lymphoma. Nat Rev Clin Oncol 2010;7:doi:10.1038/nrclinonc.2010.9-c1; author reply doi:10:1038/nrclinonc.2010.9-c2.

58 Kang AS, Jones TM, Burton DR: Antibody redesign by chain shuffling from random combinatorial immunoglobulin libraries. Proc Natl Acad Sci U S A 1991;88: 11120-11123.

59 Osbourn JK, Field A, Wilton J, Derbyshire E, Earnshaw JC, Jones PT, et al: Generation of a panel of related human scFv antibodies with high affinities for human CEA. Immunotechnology 1996;2:181-196.

60 Al-Halabi L, Balck A, Michalzik M, Fröde D, Büttgenbach S, Hust M, et al: Recombinant antibody fragments allow repeated measurements of C-reactive protein with a quartz crystal microbalance immunosensor. MAbs 2013;5:140-149. 